\title{
Optical and Physical studies of Bi Doped Borate Glassy System
}

\author{
M.A. El-Sherbiny ${ }^{a}, A$. Samir $^{b}$, H. A. Abd El-Ghany ${ }^{b}$, F. Metawe ${ }^{b}$, \\ and M.M. El-Okr ${ }^{a}$ \\ ${ }^{a}$ Physics Department, Faculty of Science, Al-Azahr University, Egypt . \\ ${ }^{b}$ Engineering Physics and Mathematics Department, Faculty of \\ Engineering Shoubra, Benha University, Egypt. \\ Corresponding author: Tel: 01001529111 \\ E-mail address: sherbinypsi@yahoo.com (M.M. El-Okr)
}

\begin{abstract}
Glasses of composition $x \mathrm{Bi}_{2} \mathrm{O}_{3}-(83-x) \quad \mathrm{B}_{2} \mathrm{O}_{3}-15 \mathrm{Na}_{2} \mathrm{O}-2 \mathrm{MnO}_{2}$ with $(x=0,5,10,20$ and $25 \mathrm{~mol} \%)$ have been prepared by conventional melt quench technique. Characterization of the prepared samples has been achieved by X-ray diffraction (XRD), density and optical measurements. The XRD patterns of all the samples showed broad humps typical for amorphous systems. Density and molar volume have been determined and it is found that both are increased with increasing of $\mathrm{Bi}_{2} \mathrm{O}_{3}$ content. The effect of $\mathrm{Bi}_{2} \mathrm{O}_{3}$ content on the optical absorption spectra was investigated in the wavelength range190$1100 \mathrm{~nm}$.The fundamental absorption edge has been identified where it exhibits red shift by increasing $\mathrm{Bi}_{2} \mathrm{O}_{3}$ content and band tail width follow opposite trend. The optical band gap $\left(\mathrm{E}_{\mathrm{g}}\right)$ values of the investigated glasses are found to lie in the range $2.40-1.90 \mathrm{eV}$ whereas the values of $\left(\Delta \mathrm{E}_{\mathrm{e}}\right)$ lie in the range $0.66-1.436 \mathrm{eV}$. Some other physical properties also reported.
\end{abstract}

\section{Introduction}

Boric oxide, $\mathrm{B}_{2} \mathrm{O}_{3}$, is one of the most important glass formers and flux materials [1-4]. It is a particularly suitable optical material because of its high transparency, low melting point, high thermal stability, different coordination numbers, easy for fabrication, shaping and mass production [5-7].

Bismuth oxide, $\mathrm{Bi}_{2} \mathrm{O}_{3}$, cannot be considered as network former because of the small field strength of $\mathrm{Bi}^{3+}$ ion, however in combination with $\mathrm{B}_{2} \mathrm{O}_{3}$, glass formation is possible in a relatively large composition range [8-10]. Borate 
glasses containing $\mathrm{Bi}_{2} \mathrm{O}_{3}$ exhibits high refractive index, large polarizability and high optical basicity. So it has potential applications in the field of glass ceramics, optical and electronic devices, thermal and mechanical sensors, smart windows and superconducting materials [11-17]. Manganese ions have strong effect on glass properties such as optical, magnetic and electrical properties [18].

The present work aims to study the effect of replacement of $\mathrm{B}_{2} \mathrm{O}_{3}$ with $\mathrm{Bi}_{2} \mathrm{O}_{3}$ content on the physical properties such as density, molar volume, optical behavior in $x \mathrm{Bi}_{2} \mathrm{O}_{3}-(83-x) \mathrm{B}_{2} \mathrm{O}_{3}-15 \mathrm{Na}_{2} \mathrm{O}-2 \mathrm{MnO}_{2}$ with $(x=0,5,10,20$ and $25 \mathrm{~mol} \%$ ) glassy system.

\section{Experimental}

\subsection{Glass Preparation}

The glass system under investigation has the general formula: $x \mathrm{Bi}_{2} \mathrm{O}_{3}-(83-x) \mathrm{B}_{2} \mathrm{O}_{3}-15 \mathrm{Na}_{2} \mathrm{O}-2 \mathrm{MnO}_{2}$ with $(x=0,5,10,20$ and $25 \mathrm{~mol} \%)$ have been prepared by conventional melt-quenching technique. Analytical grade chemicals of $\mathrm{Bi}_{2} \mathrm{O}_{3}, \mathrm{H}_{3} \mathrm{BO}_{3}, \mathrm{Na}_{2} \mathrm{Co}_{3}$ and $\mathrm{MnO}_{2}$ were used in preparation. Appropriate quantities of the chemicals were mixed in agate mortar and melted in an open porcelain crucible in a programmable electric furnace at the temperature range $1000-1100^{\circ} \mathrm{C}$ for 1 hour depending on glass compositions. The mixture was shaken frequently to ensure the homogeneity. The molten liquid was quenched in air by pouring onto a preheated brass plate to avoid breaking of the samples due to thermal strains and pressing it quickly with another brass plate. The glasses were then immediately transferred to another furnace kept at $300^{\circ} \mathrm{C}$ and annealed for $3 \mathrm{~h}$ in order to eliminate the internal mechanical stress produced by rapid cooling of the melt to room temperature. Apart of the prepared samples were selected and polished carefully with fine emery paper in order to study their optical properties.

\subsection{Glass Characterization}

The amorphous nature of all samples was firstly examined by X-Ray diffraction (XRD) at room temperature using nickel- filtered $\mathrm{Cu}-\mathrm{K} \alpha$ radiation, Philips PW3050/60 diffractometer.

The densities of the glass samples were measured by applying conventional Archimedes method with toluene as the immersion liquid $\left(\rho_{0}=\right.$ $\left.0.868 \mathrm{~g} / \mathrm{cm}^{3}\right)$ and a single pan electric balance. The density $\left(\rho_{\text {glass }}\right)$ was calculated using the formula [19]. 


$$
\rho=\left[\frac{W_{\text {air }}}{W_{\text {air }}-W_{l}}\right] \rho_{\mathrm{o}}
$$

where, $\rho_{0}$ is the density of the liquid, $\rho$ is the density of the glass sample, $W_{\text {air }}$ and $W_{L}$ are the weight of the glass in air and liquid respectively. The molar volume $\left(V_{M}\right)$ was calculated according to the relation [14].

$$
V_{M}=\frac{M_{W}}{\rho_{\text {glass }}}
$$

where, $M_{w}$ is the molecular weight of the glass samples. Density data were used to estimate the oxygen packing density (OPD) by using the formula [14].

$$
O P D=\frac{\rho}{M_{w}} \times n
$$

where $\mathrm{n}$ is the number of oxygen atoms per unit formula. The ionic concentration $(\mathrm{N})$ of Mn ion can be obtained through [20].

$$
N\left(\text { ions } / \mathrm{cm}^{3}\right)=\frac{x \rho N_{A}}{M_{w}}
$$

where $\mathrm{x}$ is the mole fraction of transition metal oxide, $\mathrm{N}_{\mathrm{A}}$ is the Avogadro's number. Obtained values were used to evaluate other related physical properties:

$$
\begin{aligned}
& \text { Polaron radius, } r_{\mathrm{p}}\left(\mathrm{A}^{\circ}\right)=1 / 2(\Pi / 6 N)^{1 / 3} \\
& \text { Inter ionic distance, } r_{\mathrm{i}}\left(\mathrm{A}^{\circ}\right)=(1 / N)^{1 / 3} \\
& \text { Field strength, } F\left(\mathrm{~cm}^{-2}\right)=Z / r_{p}{ }^{2}
\end{aligned}
$$

\subsection{Optical Measurements}

The optical absorption spectra of the glass samples were recorded at room temperature using (JENWAY 6405 UV/Vis Spectrophotometer) in the wavelength range $(190-1100 \mathrm{~nm})$.

\section{Results and Discussion.}

XRD patterns of the prepared samples are shown in Fig.(1), the patterns show no sharp peaks but broad humps indicating the amorphous nature of the prepared samples.

The density and molar volume are strongly related to the glass structure, distribution of the structural units, compactness, cross linking. The atomic weight of the constituents play principle role in determining the above mentioned 
parameters. Thus, replacement of light elements by heavy ones in the glass can cause an increase in the density that may show a linear dependence on the compositions [17]. The estimated values of the measured density ( $\rho)$ as well as the calculated molar volume $\left(\mathrm{V}_{\mathrm{M}}\right)$ are listed in Table1 and shown in Fig.(2). The obtained results reveal that, the density increases from 2.17 to $4.74 \mathrm{~g} / \mathrm{cm}^{3}$, and the molar volume increases from 31.64 to $35.34 \mathrm{~cm}^{3} / \mathrm{mol}$. as the $\mathrm{Bi}_{2} \mathrm{O}_{3}$ content increases at the expense of the $\mathrm{B}_{2} \mathrm{O}_{3}$ content as shown in Fig.(2). The increase in the density by increasing $\mathrm{Bi}_{2} \mathrm{O}_{3}$ content is most likely related to the replacement of $\mathrm{B}$ (atomic mass 10.811) by $\mathrm{Bi}$ (atomic mass 208.98). Generally the molar volume showed; follow opposite pattern to that of density. However, in many cases both follow one common pattern where both increases or decreases by changing the composition. In the present system density and molar volume increases by increasing $\mathrm{Bi}_{2} \mathrm{O}_{3}$ content. This can be accounted by considering that we have two competing factors, the atomic weights and the number of nonbridging oxygen (NBO) which leads to increase in the molar volume i.e. formation of open structure. This behavior was reported earlier for many glass systems $[13,14,17]$. The variation of density, molar volume and oxygen packing density, ionic concentration of $\mathrm{Mn}$ ion, inter ionic distance, polaron radius and field strength with $\mathrm{Bi}_{2} \mathrm{O}_{3}$ content are shown in (Figs. 2-6) respectively and listed in Table (1). It is evident that the oxygen packing density (OPD) decreases with increasing of $\mathrm{Bi}_{2} \mathrm{O}_{3}$ content. In this respect the obtained values of oxygen packing density is consistent with the above explanation. This indicates that the structure becomes less tightly packed and the degree of disorder increases as $\mathrm{Bi}_{2} \mathrm{O}_{3}$ content increased. This behavior is consistent with results observed in reference [14, 21].

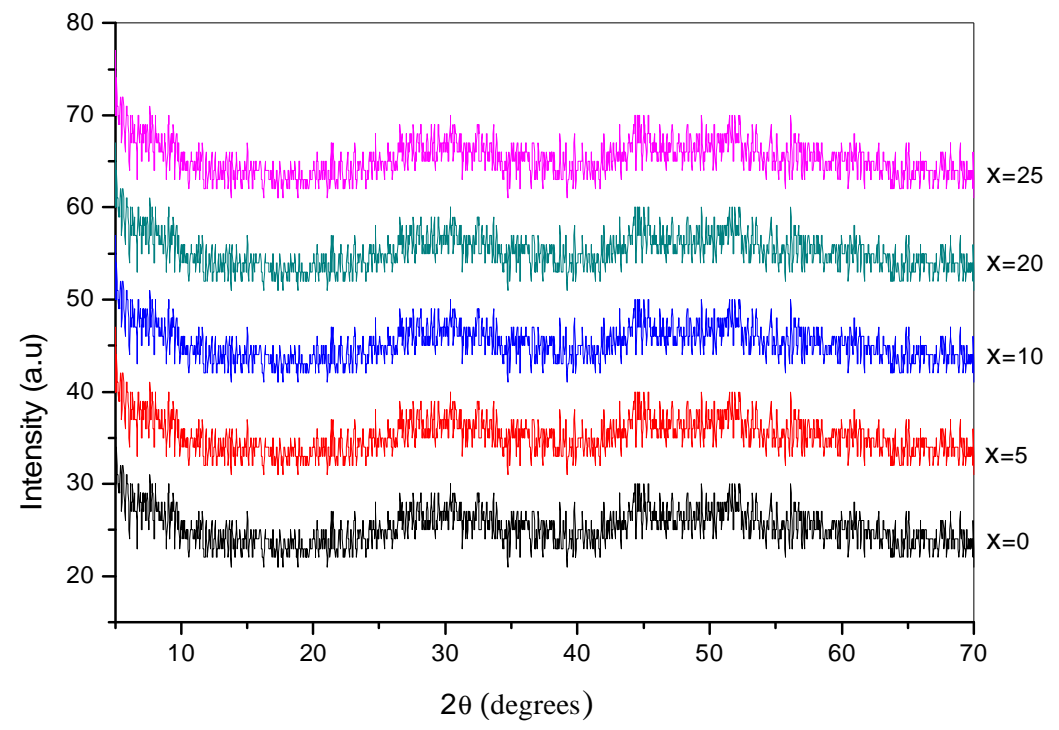

Fig.(1): XRD spectra of the prepared samples. 


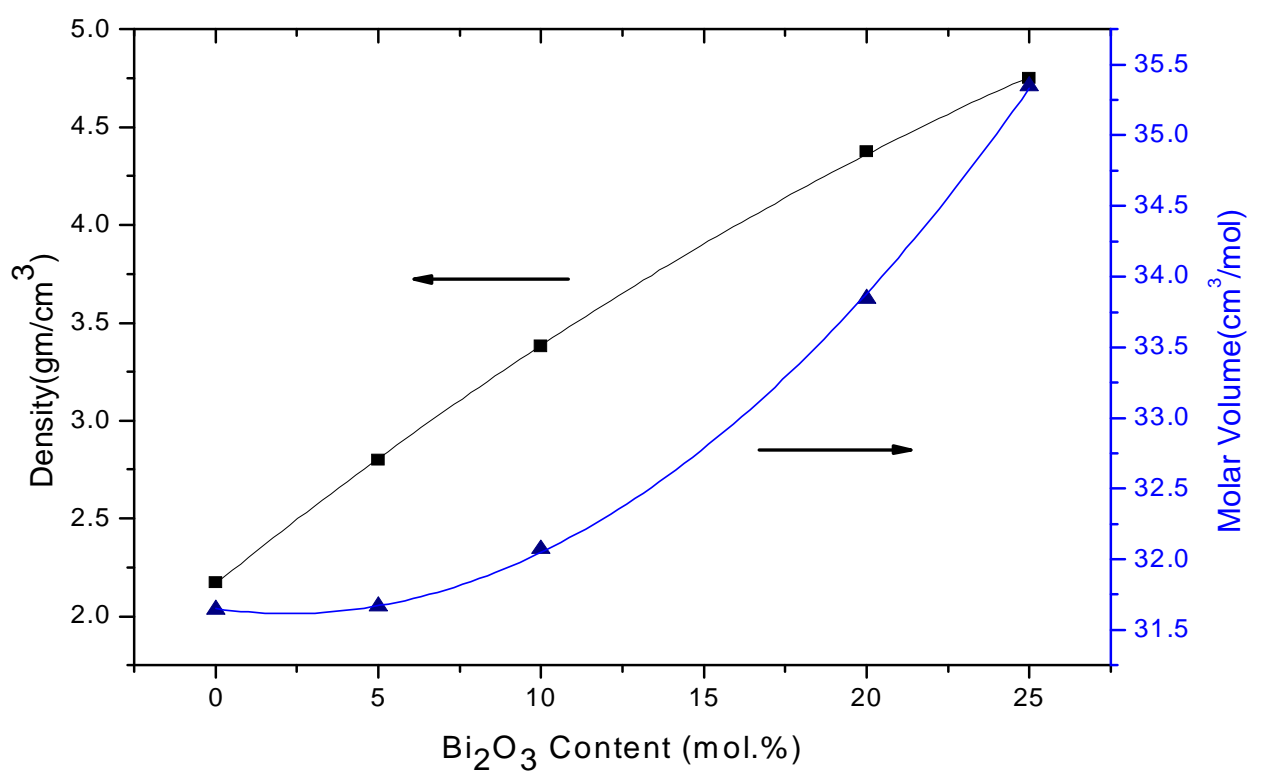

Fig.(2): Variation of density $(\rho)$ and the molar volume $\left(\mathrm{V}_{\mathrm{M}}\right)$ with composition of $\mathrm{Bi}_{2} \mathrm{O}_{3}$.

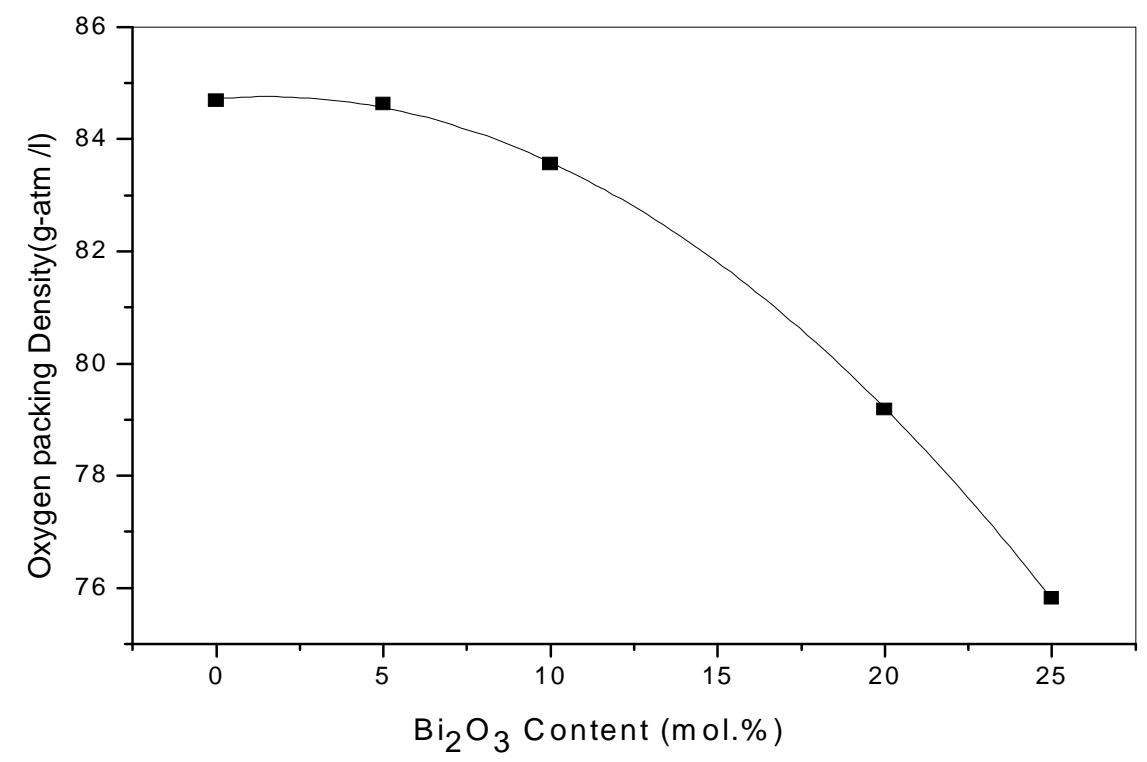

Fig.(3): Variation of oxygen packing density (OPD) with composition of $\mathrm{Bi}_{2} \mathrm{O}_{3}$. 


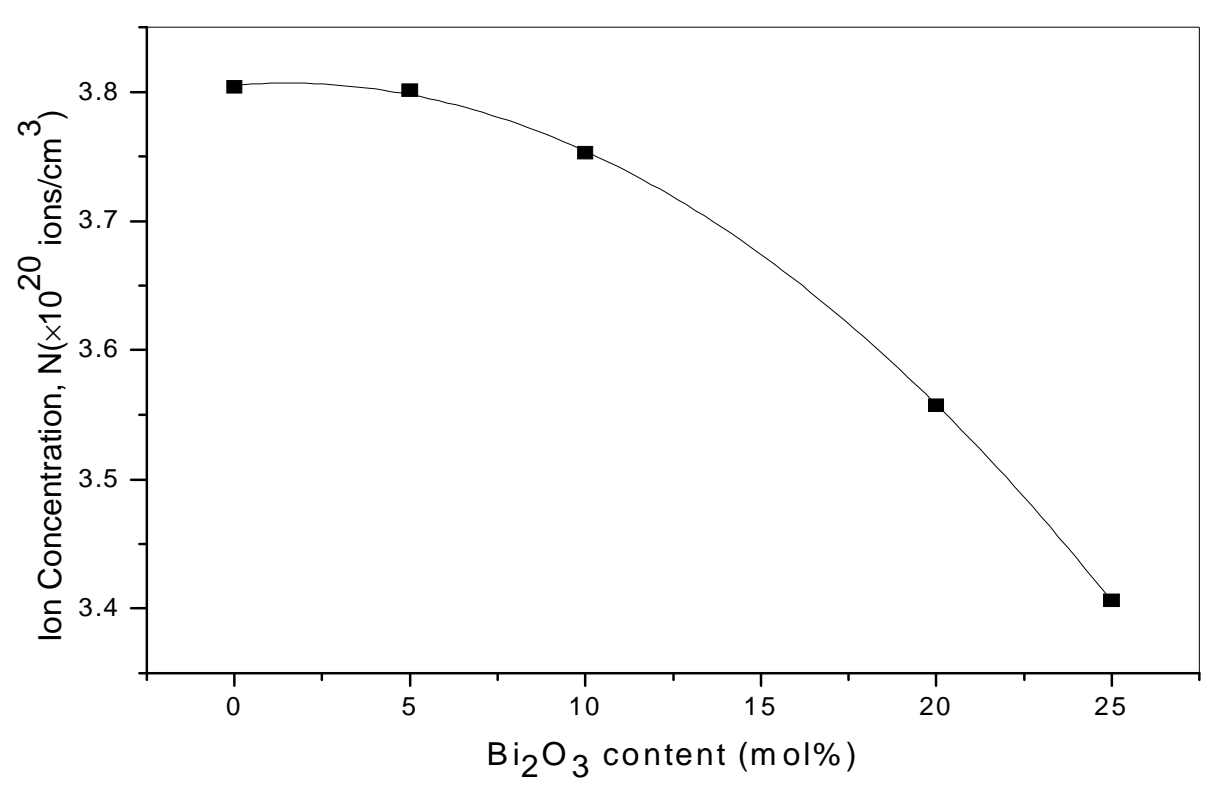

Fig.(4): Variation of $\mathrm{Mn}$ ion concentration (N) with composition of $\mathrm{Bi}_{2} \mathrm{O}_{3}$.

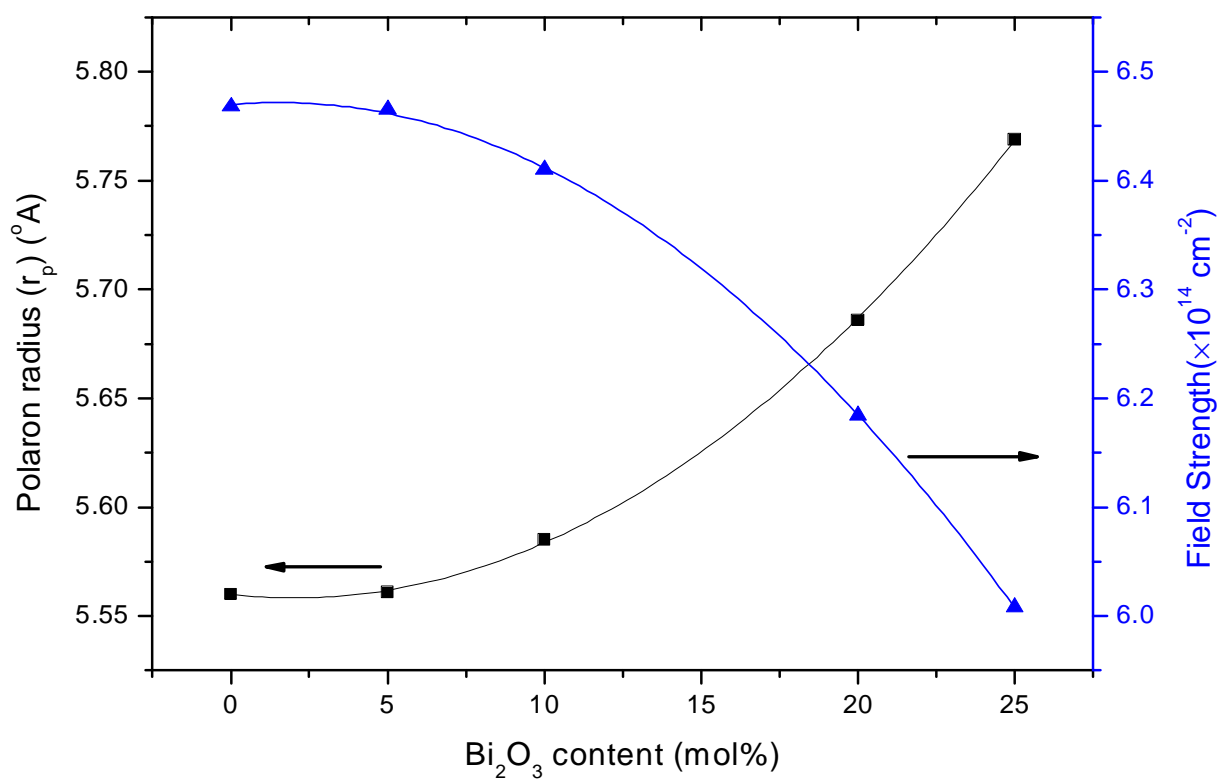

Fig.(5): Variation of Polaron radius $\left(\mathrm{r}_{\mathrm{p}}\right)$ and Field strength $(\mathrm{F})$ with composition of $\mathrm{Bi}_{2} \mathrm{O}_{3}$. 


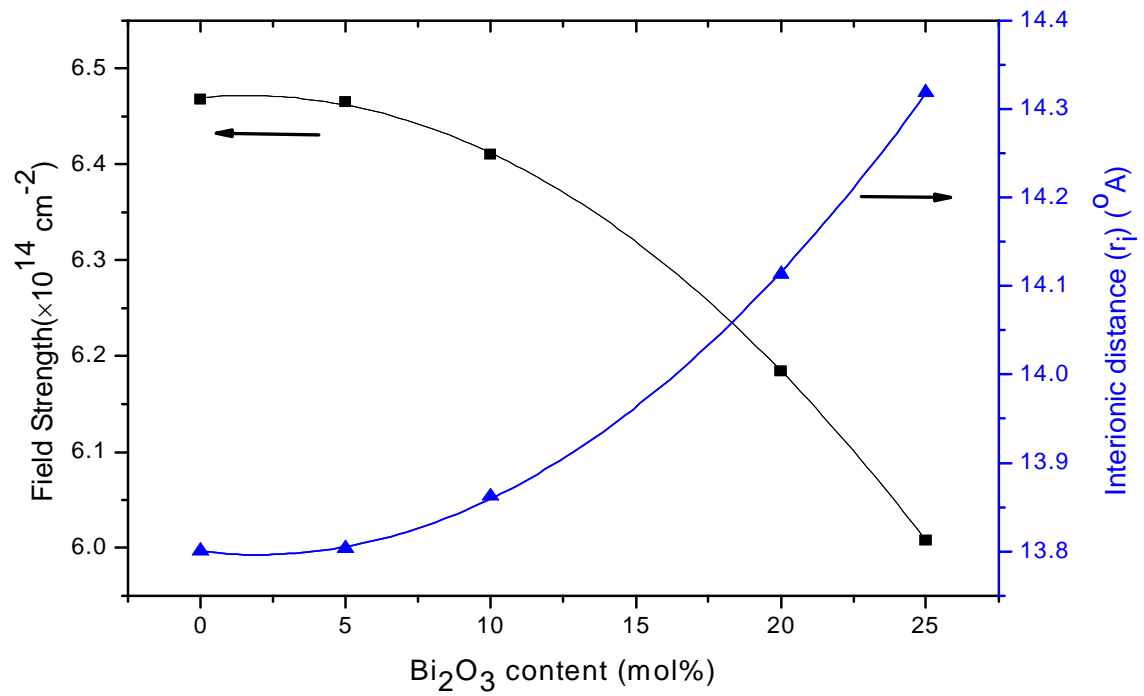

Fig.(6): Variation of interionic distance $\left(\mathrm{r}_{\mathrm{i}}\right)$ and Field strength(F) with composition of $\mathrm{Bi}_{2} \mathrm{O}_{3}$.

Table (1): Physical properties of $x \mathrm{Bi}_{2} \mathrm{O}_{3}-(83-x) \mathrm{B}_{2} \mathrm{O}_{3}-15 \mathrm{Na}_{2} \mathrm{O}-2 \mathrm{MnO}_{2}$ glassy system .

\begin{tabular}{|l|c|c|c|c|c|}
\hline \multirow{2}{*}{ Physical property } & \multicolumn{5}{|c|}{ Glass Sample } \\
\cline { 2 - 6 } & $\mathbf{X = 0}$ & $\mathbf{X = 5}$ & $\mathbf{X = 1 0}$ & $\mathbf{X = 2 0}$ & $\mathbf{X = 2 5}$ \\
\hline Average molecular weight, $M(\mathrm{~g})$ & 68.81 & 88.63 & 108.45 & 148.08 & 167.90 \\
\hline Density, $\rho\left(\mathrm{gm} / \mathrm{cm}^{3}\right)$ & 2.17 & 2.79 & 3.38 & 4.37 & 4.74 \\
\hline Molar volume, $V_{M}\left(\mathrm{~cm}^{3}\right)$ & 31.64 & 31.66 & 32.07 & 33.84 & 35.34 \\
\hline Oxygen packing density, $O P D(g$-atom $/ \mathrm{l})$ & 84.68 & 84.62 & 83.55 & 79.18 & 75.81 \\
\hline Mn ion concentration, $N\left(x 10^{20}\right.$ ions $\left./ \mathrm{cm}^{3}\right)$ & 3.80 & 3.80 & 3.75 & 3.55 & 3.40 \\
\hline Poloron radius, $r_{p}(\AA)$ & 5.56 & 5.56 & 5.58 & 5.68 & 5.76 \\
\hline Interionic distance, $r_{i}(\AA)$ & 13.80 & 13.80 & 13.86 & 14.11 & 14.31 \\
\hline Field strength, $F\left(x 10^{14} \mathrm{~cm}^{-2}\right)$ & 6.46 & 6.46 & 6.41 & 6.18 & 6.00 \\
\hline Optical energy gap, $E_{g}(\mathrm{eV})$ & 2.40 & 2.28 & 2.08 & 1.94 & 1.90 \\
\hline Urbach energy, $\Delta E_{e}(\mathrm{eV})$ & 0.66 & 0.82 & 1.10 & 1.37 & 1.43 \\
\hline
\end{tabular}

\subsection{Optical absorption studies}

The optical absorption spectra of all the samples in the wavelength range 190-1100 nm are displayed in Fig.(7). The absorption coefficient $\alpha$ (v), below and near the edge of each curve was determined using the relation [22].

$$
\alpha=\left(\frac{1}{d}\right) \ln \left(\frac{I_{0}}{I}\right)=2.303 \frac{A}{d}
$$


where $I_{0}$ and $I$ are the intensities of the incident and transmitted beams, respectively, $\mathrm{A}$ is the absorbance and $\mathrm{d}$ corresponds to thickness of each sample. The factor $\ln \left(\mathrm{I}_{0} / \mathrm{I}\right)$ is the absorbance. The relation between $\alpha(v)$ and the photon energy of the incident radiation, hv was interpreted by Davis and Mott and can be written in general form as [22].

$$
\alpha h v=B\left(h v-E_{g}\right)^{n}
$$

where $B$ is constant called band tailing parameter, $E_{g}$ is the energy of the optical band gap, $\mathrm{n}$ depends on the type of transition (direct or indirect) taking the values $\mathrm{n}=2,3,1 / 2,1 / 3$ which corresponding to indirect allowed, indirect forbidden, direct allowed, and direct forbidden transitions respectively, $\mathrm{n}$ depends also on nature of the material (crystal or amorphous). For amorphous materials, indirect transitions are valid according to Tauc relation i.e. the power part $n=2$. By plotting $(\alpha h v)^{1 / 2}$ as a function of photon energy hv, the optical energy band gap $\left(\mathrm{E}_{\mathrm{g}}\right)$ can be determined by extrapolating the linear region of the curve to the (hv) axis where $(\alpha h v)^{1 / 2}=0$ as shown in fig. 8 . The estimated values are listed in table1.The relation between $\alpha(v)$ and Urbach energy $\left(\Delta \mathrm{E}_{\mathrm{e}}\right)$ is given by the well known Urbach relation [22].

$$
\alpha(v)=\alpha_{o} \exp \left[h v / \Delta \mathrm{E}_{\mathrm{e}}\right]
$$

where $\alpha_{0}$ is constant and $\Delta \mathrm{E}_{\mathrm{e}}$ is usually interpreted as the width of the tail of the localized states in the band gap and hv is the incident photon energy. Urbuch plots Fig. ( ) 9 are the plots where the natural logarithm of absorption coefficients, $\ln \alpha$, is plotted against photon energy, hv. The values of Urbach energy $\left(\Delta \mathrm{E}_{\mathrm{e}}\right)$ were calculated by determining the slopes of the linear portion of the curves and taking their reciprocals. The values of $\Delta \mathrm{E}_{\mathrm{e}}$ are listed in table1.

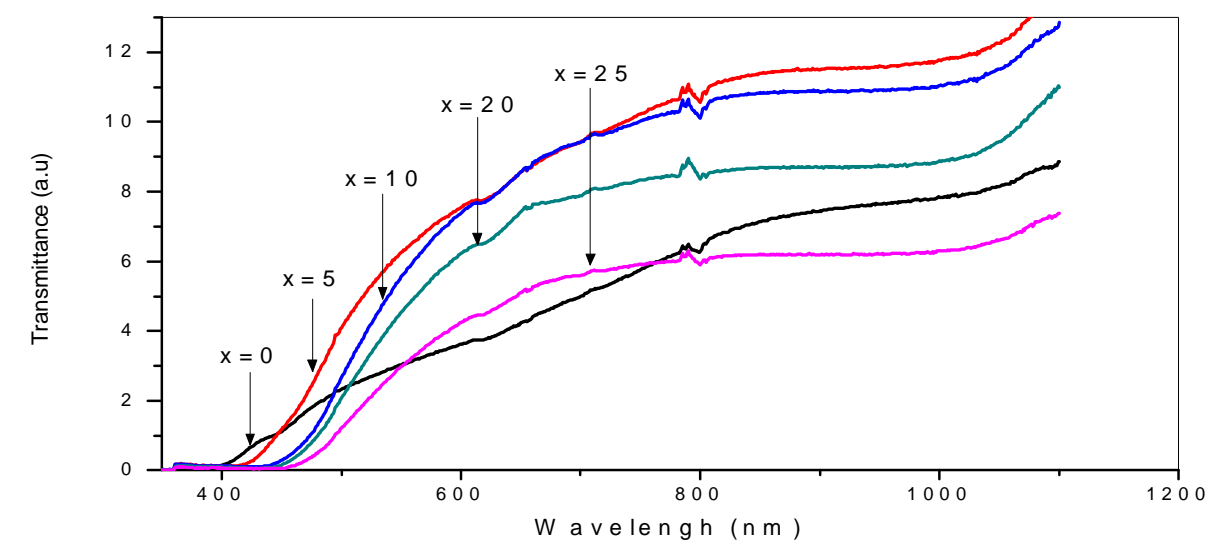

Fig.(7a): Spectral behavior of the $\mathrm{xBi}_{2} \mathrm{O}_{3}-(83-\mathrm{x}) \mathrm{B}_{2} \mathrm{O}_{3}-15 \mathrm{Na}_{2} \mathrm{O}-2 \mathrm{MnO}_{2}$ glassy system 


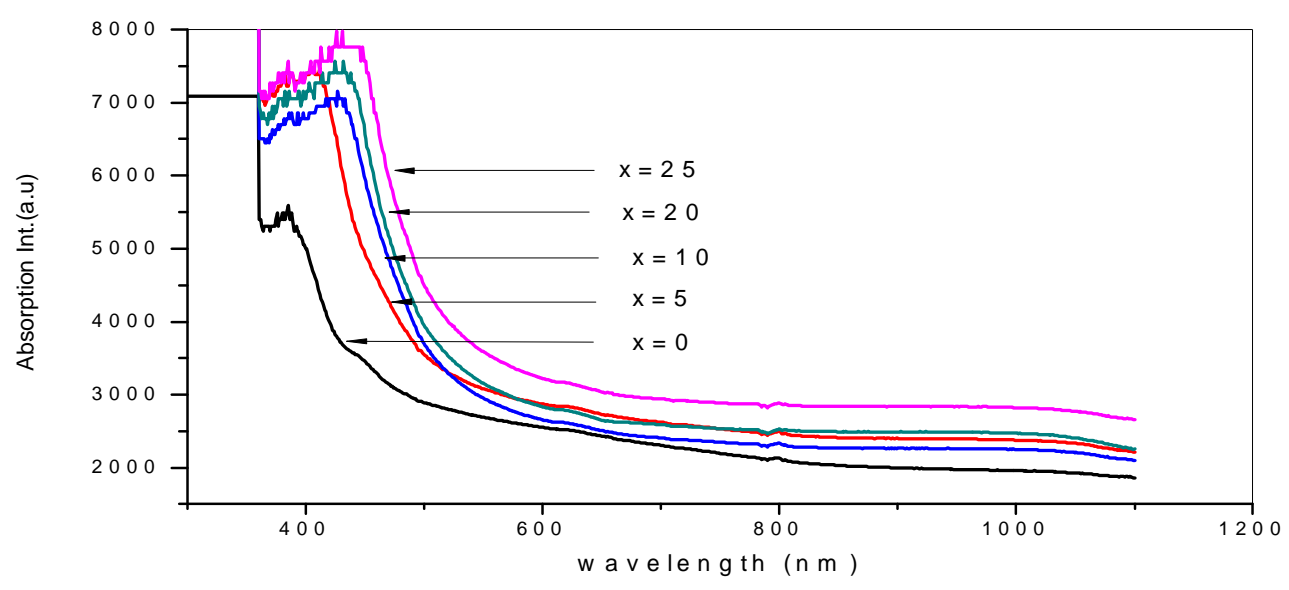

Fig.(7b): Spectral behavior of the $\mathrm{xBi}_{2} \mathrm{O}_{3}-(83-\mathrm{x}) \mathrm{B}_{2} \mathrm{O}_{3}-15 \mathrm{Na}_{2} \mathrm{O}-2 \mathrm{MnO}_{2}$ glassy system (a) Transmission (b) Absorption.

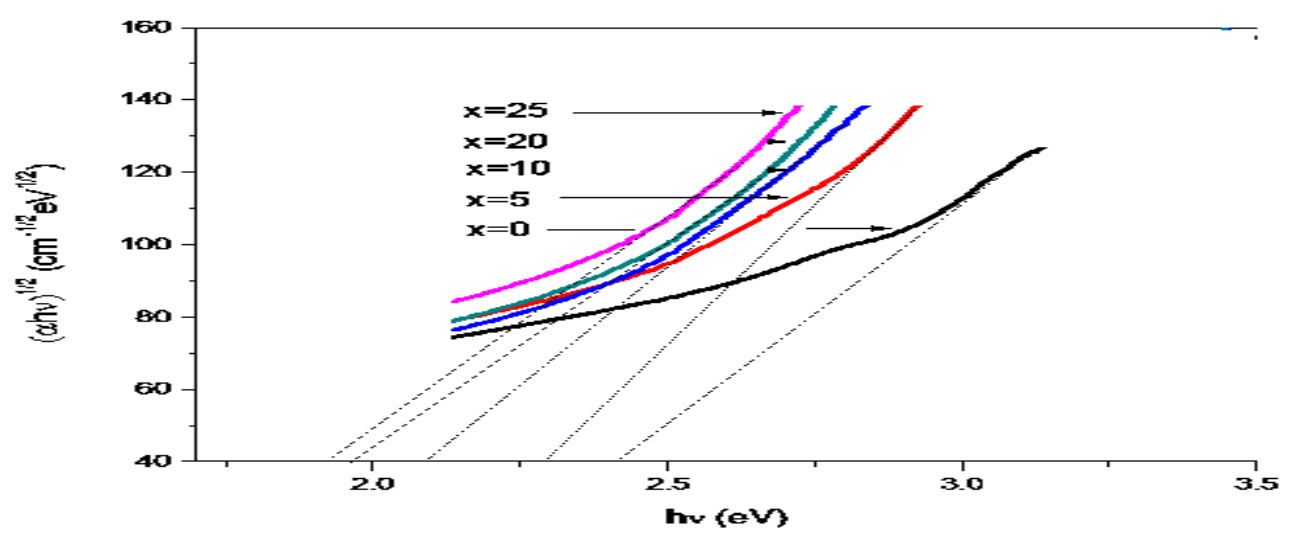

Fig.(8): Tauc's plots for $\mathrm{xBi}_{2} \mathrm{O}_{3}-(83-\mathrm{x}) \mathrm{B}_{2} \mathrm{O}_{3}-15 \mathrm{Na}_{2} \mathrm{O}-2 \mathrm{MnO}_{2}$ glassy system

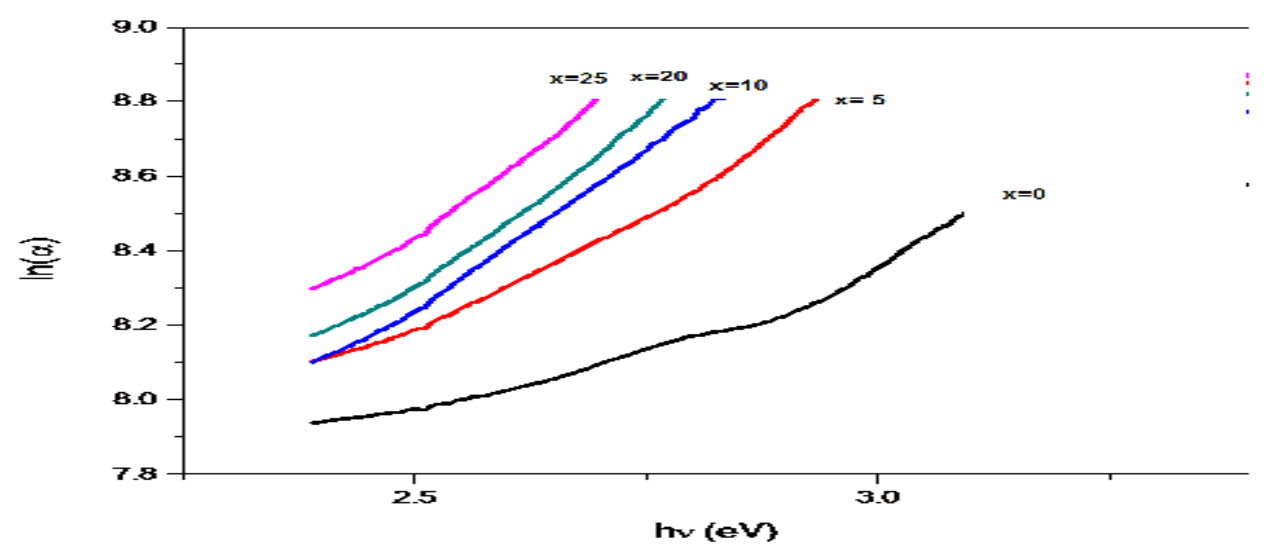

Fig.(9:) Dependence of $\ln (\alpha)$ on (hv) for $\mathrm{xBi}_{2} \mathrm{O}_{3}-(83-\mathrm{x}) \mathrm{B}_{2} \mathrm{O}_{3}-15 \mathrm{Na}_{2} \mathrm{O}-$ $2 \mathrm{MnO}_{2}$ glassy system 


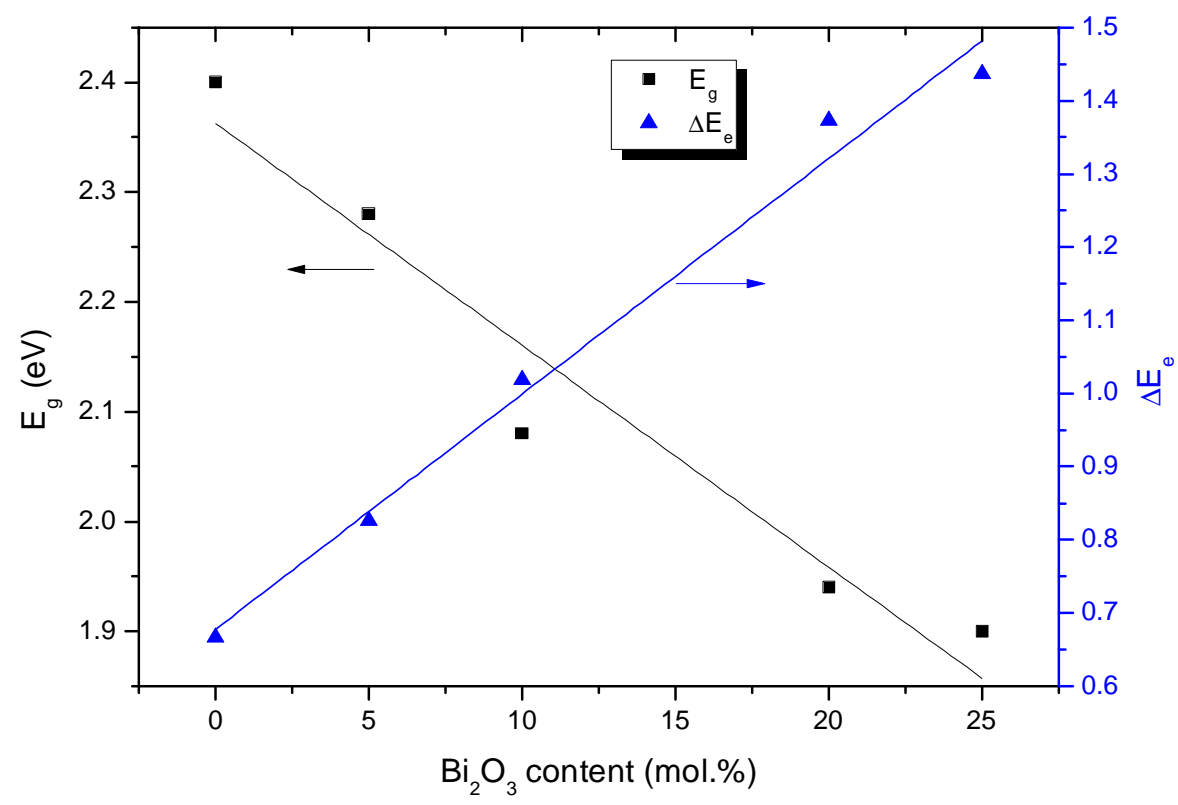

Fig.(10): Variation of optical band gap $\left(\mathrm{E}_{\mathrm{g}}\right)$ and band tail width $\left(\Delta \mathrm{E}_{\mathrm{e}}\right)$ with composition of $\mathrm{Bi}_{2} \mathrm{O}_{3}$.

From the analysis of optical absorption spectra it is found that optical absorption edge is not sharply defined which agree with the non-crystalline nature of the prepared samples. Fig.(9) reveals the indirect transition in the involved absorption mechanism, which is expected seen in glasses. The lake of translation symmetry leads to the fact that the wave vector is not good quantum number i.e. is not conserved. In the present glass system, the shift of the absorption edge or cutoff wavelength to longer wavelength and the decrease of $E_{g}$ to lower energies with increase in $\mathrm{Bi}_{2} \mathrm{O}_{3}$ content are related to the progressive increase in the concentration of non-bridging oxygen (NBO) atoms. This increase in turn gives rise to a possible decrease in the number of (B-O-B) bridging oxygen. The shift is attributed to the structural changes due to the replacement of $\mathrm{B}$ by $\mathrm{Bi}$. It is possible to assume that as the cation concentration increases, the bridging oxygens (BO) develop bonds with $\mathrm{Bi}^{3+}$ which in turn lead to the gradual breakdown of the glass network. This breakdown seems to account for the decrease in the $\mathrm{E}_{\mathrm{g}}$ value, i.e., edge shifts to longer wavelengths, as $\mathrm{Bi}_{2} \mathrm{O}_{3}$ content is increased. Such a decrease in $\mathrm{E}_{\mathrm{g}}$ can thus be attributed to decrease in the photon- assisted indirect transitions. A plot of $\mathrm{E}_{\mathrm{g}}$ and $\Delta \mathrm{E}_{\mathrm{e}}$ against $\mathrm{Bi}_{2} \mathrm{O}_{3}$ content are shown in fig.10.It is observed that $\mathrm{Eg}$ and $\Delta \mathrm{E}_{\mathrm{e}}$ follow opposite trend where the addition of $\mathrm{Bi}_{2} \mathrm{O}_{3}$ increases the degree of disorder. 


\section{Conclusions}

The glass system under investigation has the general formula: $x \mathrm{Bi}_{2} \mathrm{O}_{3}-(83-x) \mathrm{B}_{2} \mathrm{O}_{3}-15 \mathrm{Na}_{2} \mathrm{O}-2 \mathrm{MnO}_{2}$ with $(\mathrm{X}=0,5,10,20$ and $25 \mathrm{~mol} \%)$ and has been prepared by conventional melt-quenching technique. The prepared samples have been examined by different techniques including XRD, density and optical absorption spectra. The obtained results allow concluding that:

- The XRD data confirm the amorphous nature of the prepared samples.

- It is observed that the density $(\rho)$ increases with increasing $\mathrm{Bi}_{2} \mathrm{O}_{3}$ content. This increasing in density is mainly due to the difference in the atomic masses. The molar volume $\left(\mathrm{V}_{\mathrm{M}}\right)$ increases with increasing $\mathrm{Bi}_{2} \mathrm{O}_{3}$ content. Such unexpected results can be attributed to the formation of non-bridging oxygen (NBO) i.e. formation of open structure. The larger values of the radii and bond length of $\mathrm{Bi}_{2} \mathrm{O}_{3}$, compared to those of $\mathrm{B}_{2} \mathrm{O}_{3}$, resulted in a formation of excess free volume, which increase the overall molar volume of the glasses

- The oxygen packing density (OPD) decreases with increasing of $\mathrm{Bi}_{2} \mathrm{O}_{3}$ content. This indicates that the glass network becomes less tightly packed and the degree of disorder increases as $\mathrm{Bi}_{2} \mathrm{O}_{3}$ content increases.

- The optical band gap energy $\left(\mathrm{E}_{\mathrm{g}}\right)$ decreases with increasing of $\mathrm{Bi}_{2} \mathrm{O}_{3}$ content. This may be attributed to the formation of non-bridging oxygen (NBO). It is observed that $\left(\Delta \mathrm{E}_{\mathrm{e}}\right)$ increases with increasing $\mathrm{Bi}_{2} \mathrm{O}_{3}$ are due to the addition of $\mathrm{Bi}_{2} \mathrm{O}_{3}$ increases the disorder of the glass system.

\section{References}

1. Isabella-Ioana Oprea, Hartmut Hesse, Klaus Betzler, Optical Materials, 26, 235 (2004).

2. Shashidhar Bal, N.Srinivasa Rao, Syed Rahman, Solid State Sciences, 10, 326 (2008).

3. G. Lakshminarayana, S. Buddhudu, Spectrochimica Acta Part, A 63, 295 (2006).

4. Petru Pascuta, Gheorghe Borodi, Eugen Culea, Journal of Non-Crystalline Solids, 354, 5475 (2008).

5. L. Srinivasa Rao, M. Srinivasa Reddy, M.V. Ramana Reddy, N. Veeraiah, Physica, B 403, 2542 (2008).

6. I. Ardelean, Simona Cora, Raluca Ciceo Lucacel, Octavia Hulpus, Solid State Sciences, 7, 1438 (2005).

7. N. Murase, Y. Kawasaki, A. Tomita, Journal of Luminescence, 98, 301 (2002).

8. S. Simon, I. Ardelean, S. Filip, I. Bratu, I. Cosma, Solid Stat Communications, 116, 83 (2000). 
9. Huiyan Fan, Guonian Wang, Lili Hu, Solid State Sciences, 111, 2065 (2009).

10. Petru Pascuta, Simona Rada, Gheorghe Borodi, Maria Bosca, Lidia Pop, Eugen Culea, Journal of Molecular Structure, 924, 214 (2009).

11. A. Dutta, A. Ghosh, Journal of Non-Crystalline Solids, 353, 1333 (2007).

12. Lucian Baia, Razvan Stefan, Wolfgang Kiefer, Jurgen Popp, Simion Simon, Journal of Non-Crystalline Solids, 303, 379 (2002).

13. El Sayed Moustafa, Yasser B. Saddeek, Essam R. Shaaban, Journal of Physics and Chemistry of Solids, 69, 2281 (2008).

14. D. Saritha, Y. Markandeya, M. Salagram, M. Vithal, A.K. Singh, G. Bhikshamaiah, Journal of Non-Crystalline Solids, 354, 5573 (2008).

15. Xinyu Zhao, Xiaoli Wang, Hai Lin, Zhiqiang Wang, Physica, B 390, 293 (2007).

16. S.Sindhu, S.Sanghi, A.Agarwal, V.P.Seth, N.kishore, Material Chemistry and Physics, 90, 83 (2005).

17. Yasser B. Saddeek, Essam R. Shaaban, El Sayed Moustafa, Hesham M. Moustafa, Physica, B 403, 2399 (2008).

18. M. Srinivasa Reddy, G. Murali Krishna, N. Veeraiah, Journal of Physics and Chemistry of Solids, 67, 789 (2006).

19. G. Sharma, V.Rajendran, K.S.Thind, Gagandeep Singh, Amarjit Singh, Physica, B 404, 3371 (2009).

20. A.S. Rao, Y.N. Ahammed, R.R. Reddy, T.V.R. Rao, Optical Materials, 10, 245 (1998).

21. Guojun Gao, Lili Hu, Huiyan Fan, Guonian Wang, Kefeng Li, Suya Feng, Sijun Fan, Huiyu Chen, Optical Materials, 32, 159 (2009).

22. Shashidhar Bale, Syed Rahman, Journal of Non-Crystalline Solids, 355, 2127 (2009). 